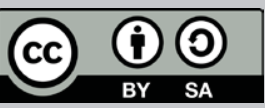

Godoy, S. (2021). La okupación cultural urbana como emergente de las transformaciones post-industriales. El caso del Galpón Okupa de Rosario (Argentina). Collectivus. Revista de Ciencias Sociales, 8 (2), 137-166. https://doi.org/10.15648/Collectivus.vol8num2.2021.3133

do

\title{
ShCOLLCTIVLS
}

\section{La okupación cultural urbana como emergente de las transformaciones post-industriales. El caso del Galpón Okupa de Rosario (Argentina)}

Cultural urban squat as emergent of post-industrial transformations. The case of the Galpón Okupa Rosario (Argentina)

\section{SEBASTIÁN GODOY*}

D HTTPS://ORCID.ORG/0000-0002-6766-8393

\footnotetext{
* Doctor en Historia. Facultad de Humanidades y Artes (FHyA), Universidad Nacional de Rosario (UNR). Instituto de Estudios Críticos en Humanidades (IECH), Consejo Nacional de Investigaciones Científicas y Técnicas (CONICET). Rosario, Argentina (CP: 2000). Correo electrónico: sebasgodoy13@gmail.com
} 


\title{
RES U M E N
}

El presente artículo ensaya un acercamiento al Galpón Okupa, un centro cultural producto de la ocupación de un inmueble ferroviario en la ciudad de Rosario, entre 1997 y 1998. Se intenta reconstruir el proceso de formación, organización, resistencia, visibilización y desalojo de ese centro cultural. La metodología del trabajo combina entrevistas en profundidad, fuentes periodísticas, documentos oficiales y materiales audiovisuales. La singularidad del caso radica en su papel en las definiciones culturales del frente costero de Rosario. En este trabajo se postula que, surgido de la desafectación de la interfaz ferroportuaria y clausurado por la reconversión de esa misma interfaz, el Galpón Okupa es un emergente de las transformaciones urbanas post-industriales.

Palabras clave: okupación, centro cultural, conflicto, frente costero, ciudad post-industrial.

\begin{abstract}
A B S T R A C T
This article tries an approach to the Galpón Okupa, a cultural center product of the occupation of a railway building in the city of Rosario, between 1997 and 1998. It attempts to reconstruct the process of formation, organization, resistance, visibility and eviction of that center cultural. The methodology combines in-depth interviews, journalistic sources, official documents and audiovisual materials. The singularity of the case lies in its role in the cultural definitions of the waterfront of Rosario. In is postulated that, shaped from the disaffection of the railway and port interface and evicted by the reconversion of that same interface, the Galpón Okupa is an emergent of the post-industrial urban transformations.
\end{abstract}

Keywords: squat, cultural center, conflict, waterfront, post-industrial city. 


\section{Le squat culturel urbain comme émergeant des transformations post-industrielles. Le cas du Galpón Okupa de Rosario (Argentine)}

\section{RÉ S U M É}

Cet article tente une approche au Galpón Okupa, un centre culturel résultant de l'occupation d'un bâtiment ferroviaire dans la ville de Rosario entre 1997 et 1998. Il tente de reconstruire le processus de formation, d'organisation, de résistance, de visibilité et d'expulsion de ce centre culturel. La méthodologie combine des entretiens approfondis, des sources journalistiques, des documents officiels et du matériel audiovisuel. La singularité de ce cas réside dans son rôle au sein des définitions culturelles de la côte du fleuve de Rosario. Ce travail postule que, né de la désaffection de l'interface ferroviaire-portuaire et fermé par la reconversion de cette même interface, le Galpón Okupa est un émergent des transformations urbaines post-industrielles.

Mots-clés: squat, centre culturel, conflit, front côtier, ville post-industrielle.

\section{Okupação cultural urbana como emergente de transformações pós-industriais. O caso do Galpón Okupa do Rosário (Argentina)}

\section{RES U M O}

Este artigo tenta uma aproximação ao Galpón Okupa, um centro cultural efeito da ocupação de um edifício ferroviário na cidade de Rosario entre os anos 1997 e 1998. Ela tenta reconstruir o processo de formação, organização, resistência, visibilidade e despejo deste centro cultural. A metodologia combina entrevistas em profundidade, fontes jornalísticas, documentos oficiais e materiais audiovisuais. A singularidade do caso reside em seu papel nas definições culturais da costa do rio de Rosário. Este artigo postula que, aperto pela desafeição da interface ferrovia-porto e fechado pela reconversão dessa mesma interface, o Galpón Okupa é um emergente das transformações urbanas pós-industriais.

Palavras chave: okupação, centro cultural, conflito, frente costeiro, cidade pós-industrial. 



\section{Introducción}

El fenómeno global de los espacios okupa se integra en dinámicas que lo posicionan como un movimiento social urbano tendiente a la autogestión, lo comunitario y la realización de actividades culturales (Martínez, 2020). Asimismo, las prácticas de okupación (squatting) conforman experiencias situadas, afectadas por las dinámicas particulares de las ciudades en las que se desenvuelven. El caso aquí presentado oscila entre ambas escalas. El Galpón Okupa, también llamado Centro Kultural Independiente (CKI) ${ }^{1}$, constituyó un espacio dedicado a las actividades artísticas y culturales, producto de la ocupación de un inmueble ferroviario en la localidad de Rosario entre 1997 y 1998. Por un lado, el caso presenta similitudes con el movimiento okupa forjado en las metrópolis europeas desde la década de 1970 (Cattaneo y Martínez, 2014). Por otro, adquiere su especificidad como un emergente de la transformación urbana post-industrial de Rosario, condensada en la adecuación de su frente costero a la economía de servicios (Aboal, Crespi y Rubalcaba, 2015). En concreto, la existencia del Galpón Okupa se trama en las definiciones culturales de las antiguas infraestructuras logísticas de la urbe. Su condición de posibilidad fue la desafectación y el abandono de la interfaz ferroportuaria. Su condición de clausura fue la rehabilitación de esa misma interfaz ferroportuaria como huella patrimonial de un paisaje cultural (Sabaté Bel, 2010).

1 Nos referiremos al espacio ocupado intercalando ambos nombres (Galpón Okupa y CKI). 
Desde finales del siglo XX, la ciudad de Rosario atravesó un proceso de conversión de sus infraestructuras logísticas ribereñas en dispositivos culturales y recreativos. Al igual que otras costaneras de ciudades post-industriales, el waterfront rosarino incorporó piezas ferroportuarias al desarrollo urbano (Bruttomesso, 1993; Meyer, 1999; Marshall, 2001) para la provisión de servicios. El alto perfil de ese frente costero posibilitó la observación de dinámicas propias del capitalismo post-fordista y de acumulación flexible (Harvey, 1998). Entre ellos se destacan la urbanización como forma espacial de valorización del capital (Harvey, 2009), el marketing urbano (Ward, 1998) y la gentrificación (Smith, 2013). A escala nacional, el desmantelamiento del sistema ferroviario argentino durante el menemismo, la modernización de los puertos y la posterior transferencia de sus activos a los municipios habilitaron la producción del waterfront en Rosario.

Los trazos locales de esa transformación se refieren a la recuperación del motivo histórico de la relación ciudad-río. A comienzos de la década de 1990, las Secretarías de Planeamiento y de Cultura proyectaron sobre la costa del río Paraná un encadenamiento de espacios públicos y dispositivos recreativos (Godoy, 2021a). La porción central de la ribera, de unos 4 kilómetros de largo (fig. 1), fue reconvertida por partes. Como resultado, hacia principios del siglo XXI los terrenos y edificaciones provenientes del primer modelo agroexportador se rediseñaron con miras al despliegue de una economía de la experiencia y la autenticidad (MacCannell, 1973). Simbiosis de imagen y producto urbano (Zukin, 2000), el waterfront post-industrial rosarino capitalizó aspectos culturales e históricos para su redefinición en clave recreativa y turística (Craig-Smith y Fagence, 1995; Vera, 2015).

\section{Figura 1. Ribera central de Rosario}

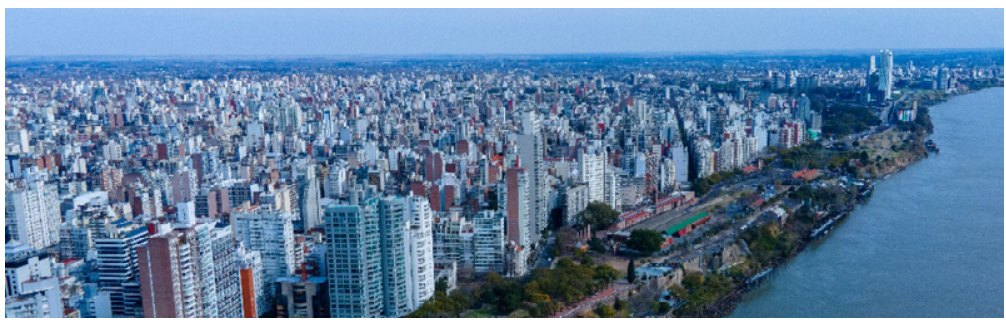

Fuente: fotografía de la empresa “CMD Rosario Drone”. 
No obstante, esa narrativa evolutiva esconde procesos de desplazamiento y desposesión material y simbólica (Janoschka, 2016; Masagualli y Bolaño, 2017) de comunidades que habitaban previamente la ribera. ${ }^{2}$ El CKI se formó en enero de 1997 y fue desalojado en agosto de 1998. Su corta existencia se cifró en un doble intersticio urbano. En primer lugar, funcionó en un inmueble ferroviario desafectado de su histórica función y carente de destino claro en relación al waterfront proyectado para el inicio del siglo XXI. Hacia mediados de la década de 1990, la estructura, que databa de la década de 1860 y se había consagrado al suministro de agua para las máquinas de los trenes (Galimberti, 2015; Bossio, 2019), se encontraba abandonada. En 1995, el Estado nacional liquidó los activos del ferrocarril y dio por terminadas sus actividades (Decreto 1039/95). En segundo lugar, el Galpón Okupa se emplazó en una porción territorial de suelo vacante, despojada de su perfil ligado al transporte fluvial y todavía no adecuada como espacio público, una categoría nueva el ordenamiento urbanístico de Rosario (Roldán y Godoy, 2017). Por entonces, antes de asumir un estatuto de publicidad (publicness) a partir de la apertura, la visibilidad y la accesibilidad (Rabotnikof, 1996), la ribera central existía como espacio libre o reserva de tierras (Fedele y Ucedo, 2012). Posiblemente, la situación bisagra de la experiencia respecto del pasado ferroportuario y del espacio público haya operado en provecho de su borradura de la historización de la ribera: luego de su desalojo por parte de fuerzas represivas, no quedaron registros oficiales de esa experiencia okupa (Roldán y Godoy, 2020).

Elpresente artículo ensaya una aproximaciónla historia del CKI como emergente cultural de la ciudad post-industrial. Primero, se repondrá el proceso de ocupación y adecuación del inmueble. Segundo, se describirá su funcionamiento como centro cultural. Tercero, se explorará la conflictividad que sostuvo con el gobierno local y nacional (intentos de negociación y allanamiento, resistencia y desalojo). Cuarto, analizará la relación del Galpón Okupa con las transformaciones urbanas

2 Por ejemplo, familias de pescadores que habitaban en la barranca del río Paraná (Roldán y Castillo, 2020). 
post-industriales, a través de su clausura y la absorción gubernamental de sus prácticas en el waterfront cultural y recreativo. Este escrito proviene de dos proyectos de investigación sostenidos por el Consejo Nacional de Investigaciones Científicas y Técnicas (CONICET) de Argentina, cuyos relevamiento documental y trabajo de campo se realizaron entre 2014 y 2020. La metodología propuesta triangula fuentes escritas (periódicos, revistas, normativas oficiales), audiovisuales (una filmación en crudo y un documental) y, principalmente, orales. El artículo cuenta con una selección de algunas de las más de 30 entrevistas cualitativas y en profundidad (Guber, 2011; Fontalvo y Díez, 2021) realizadas a informantes relacionados con el CKI: okupas, colaboradores externos, talleristas, asistentes a las actividades culturales y artistas que se presentaron en el espacio ocupado.

\section{Entrada y adecuación}

En 1995, las instalaciones del Ferrocarril Mitre ubicadas en la ribera central de Rosario dejaron de funcionar. Una de sus piezas arquitectónicas consistía en un galpón de concepción ingenieril inglesa, cuya función había sido la carga de agua a máquinas y locomotoras. De gran porte y paredes de ladrillo visto, la estructura se erigía en la proximidad de la Estación Rosario Central, entre malezas, terminales y osamentas férreas con un pasado afín. ${ }^{3}$ Desde el cese de actividades de la playa de maniobras, formaba parte de una interfaz logística desafectada. En 1996, diversos grupos de artistas frecuentaron semanalmente las inmediaciones del galpón abandonado. Bajo el nombre de Fiesta del Fuego, esos encuentros se ritualizaron, socializando técnicas de circo, teatro, murga, danza y música. Ese evento fue reseñado por una revista cultural local:

Un espectáculo de lanzamiento de fuego, baile y malabares, surgido a mediados de este año [...] y atípico: no se pasa la gorra, no hay rutinas, de modo que la improvisa-

3 La descripción de los espacios de la ribera central y su relación con las artes performáticas en Rosario, que excede los requerimientos de extensión de este artículo, puede hallarse en Godoy (2021a). 
ción es una constante. Y los participantes fluctúan entre treinta y cien. El encuentro conjuga la belleza atrayente del fuego con la experimentación musical y el goce. ${ }^{4}$

Uno de los informantes de esta investigación, Pablo T. ${ }^{5}$, enlaza esa práctica con la posterior ocupación del inmueble ferroviario por parte de artistas. En su relato, la necesidad de guarecer a los elementos utilizados en el ritual performático derivó en la entrada en el galpón: "guardábamos las cosas que quedaban de la Fiesta del Fuego en el galpón, empezamos a pasar y quedarnos un rato ahí”. Por su parte, Javier G. A. ${ }^{6}$, coincide: "hubo una migración de la Fiesta del Fuego al galpón”. Los escasos 500 metros que escinden la estructura ferroviaria del sitio de la reunión sostienen esa hipótesis.

Existe un segundo conjunto de testimonios acerca del ingreso al edificio, que lo coloca como el resultado de una reunión festiva. Txatxi ${ }^{7}$ evoca una "caravana de año nuevo" protagonizada un grupo de punks que solían merodear por "un lugar baldío y con yuyos re altos". Ferky ${ }^{8}$ sitúa la ocupación cuando "pegaron la vuelta" de dicha fiesta, a la que asistió con Txatxi. Una tercera versión infiere el goteo progresivo de individuos en el sitio, con miras a pasar el tiempo. Mauro F. ${ }^{9}$ se ubica a sí mismo entre personas "que venían del circo, de los malabares y de la calle, de lo marginal". Zeta ${ }^{10}$, añade que "conformamos una 'ranchada' inicial, nos juntábamos a tomar, a fumar, [...] nos quedábamos a dormir”.

4 Vasto Mundo, (12), diciembre de 1996, “Artistas en la vía”.

5 Artista circense, participante de la Fiesta del Fuego y del Galpón Okupa. Entrevista personal, 26/03/2014. Para agilizar la lectura, se colocarán las referencias a las entrevistas solamente en la primera mención al entrevistado. Luego, sus testimonios se transcribirán precedidos por el nombre 0 apodo con el que se presentan.

6 Perteneciente a la escena punk local, participante de la Fiesta del Fuego. Entrevista personal, 26/05/2015.

7 Perteneciente a la escena punk local, participante de la Fiesta del Fuego y del Galpón Okupa. Entrevista personal, 28/05/2015.

8 Artista circense, participante del Galpón Okupa. Entrevista personal, 23/09/2019.

9 Artista circense, participante del Galpón Okupa. Entrevista personal, 20/03/2017.

10 Participante del Galpón Okupa. Entrevista personal, 13/11/2018. 
Contrastadas, las narraciones ofrecen memorias encontradas y difusas (Portelli, 1991), yuxtaponiendo diversas prácticas y percepciones del espacio (Lefebvre, 2013). Con todo, es posible que los informantes hayan participado de distintas modulaciones de un mismo proceso. A pesar de las divergencias, pueden extraerse ciertas características que enmarcan la ocupación. Fundamentalmente su carácter paulatino y su relación con la circulación de artistas en la ribera central. Si bien el inmueble ya contaba con la presencia de individuos ${ }^{11}$, el acontecimiento descrito marca la entrada de los organizadores del centro cultural, estimado en enero de 1997 (Godoy, 2019).

Las descripciones coinciden en asignarle una duración de unas semanas al acondicionamiento del lugar, desagregado en varias tareas. Primero, la remoción de residuos y el saneamiento de las extensiones rescatadas del abandono. Ferky ilustra el pedido de elementos de limpieza realizado por sus compañeros: "prestame una escoba, prestame una pala, prestame un secador". Pablo T. explica que "un día se limpiaba, otro día se hacía un asado y otro día se avanzaba sobre otro pedazo más". Txatxi continúa: "se empezó a limpiar y se le empezó a dar forma de centro cultural”. Segundo, la instalación del mobiliario. Los entrevistados mencionan repisas, bibliotecas, mesas, sillas, colchones y electrodomésticos. Tercero, el abastecimiento de servicios. Las garrafas de gas fueron provistas colectivamente. La fuente de agua fue la red pública, adecuada a través de ciertos dispositivos. Txatxi comenta que "había ducha, termotanque y te podías bañar, también inodoro y agua corriente que venía de la calle”. En cuanto a la electricidad, Moroco, su encargado, comenta: "hicimos toda la instalación nueva [...], empezamos a poner más seguridad [...] a hacerlo más habitable, más para que vaya la gente". ${ }^{12}$ Cuarto, el establecimiento de divisiones espaciales, desagregadas en espacios comunes y habitáculos. Ivana R. ${ }^{13}$ desarrolla este punto desde su experiencia:

11 Por ejemplo, las entrevistas mencionan a "Marcela", referida también como "la Colorada", "la Colo" o "la Vieja". 
Éramos artesanos que vendíamos en las peatonales. Ahí lo conocimos al Moroco, que vivía en el Galpón y nos llevó hasta allá. Nos invitaron a vivir. Nos recibieron con mate caliente y facturas. Ese día los okupas cocinaron un guiso espectacular en una gran olla arriba de una parrilla. Había tres cocinas [...]. Nos ofrecieron unos siete compartimentos en el ala izquierda del edificio separados por entrepisos.

La fabricación de entrepisos a partir de la subdivisión de la extensión vertical fue una constante en la ocupación. Se emplearon plataformas de madera y andamios para producir las recámaras elevadas (fig. 2). La personalización de los lugares asignados, que auguraba el perfil artístico del CKI, fue otra de las tónicas convivientes. Ferky, por ejemplo, "tenía la pieza arriba, con mis posters y libros y discos que llevé”. En las antípodas de la propiedad privada, una superficie pertenecía a alguien en la medida que la usara y colocara ahí sus pertenencias. La presencia corporal y el apilamiento objetual eran condiciones necesarias, pero no suficientes para okupar. Txatxi interpreta que,

...el Galpón demandaba que había que ocupar el espacio, pero también había que sostenerlo. No era que vos llegabas al lugar y estaba todo dado. Había que entrar con la "fuerza de okupar". Vos venís ya predispuesto a okupar, por más que te encuentres con fulano, mengano, que no tiene ganas de barrer durante toda la semana o le importa tres carajos lavar los platos [...] Lo que el Galpón permite y habilita funciona para algunas personas.

El ingreso y la permanencia en el Galpón Okupa eran irrestrictos. No obstante, su misma espacialidad "demandaba” -y sus dinámicas sociales requerían- la sustentación del propio lugar y de las áreas comunes. Morar íntegramente precisaba de cierto temple, pero no era imprescindible para participar de la experiencia. La vida del CKI le debió mucho a sus colaboradores no residentes. Amalia D. ${ }^{14}$ considera que, "aunque no vivieras ahí, había una sensación de que era tu casa”. El goteo de okupas y curiosos fue nutriendo al espacio

14 Artesana y fotógrafa, participante del Galpón Okupa. Entrevista personal, 04/06/2015. 
de un conjunto de matices y trasfondos divergentes. Algunos no tenían dónde vivir. Otros, como Ferky, simplemente preferían no estar en sus casas. Unos terceros, cómodos en sus hogares, visitaban diariamente el lugar y trabajaban en su mejoramiento, invistiéndolo de cualidades positivas. Ese era el caso de Txatxi. Había quienes permanecían allí por temporadas, como Ivana R. En líneas generales, habitar implicaba el establecimiento de relaciones culturales con el entorno (Giglia, 2012; Salvatori y Terrón, 2019). Durante 1997, el Galpón Okupa halló fortaleza en su poblamiento.

\section{Figura 2. Montaje de entrepisos}

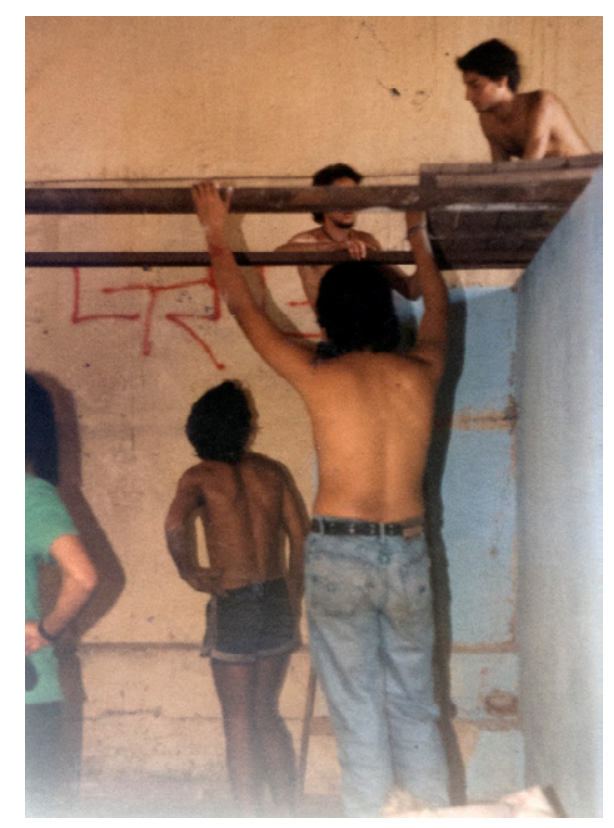

Fuente: fotografía de Inés Martino.

\section{El centro cultural}

Según Pablo T., durante la adecuación espacial "apareció gente que hacía teatro, gente que escribía, gente que pintaba [y] que no tenía lugar donde hacerlo". Se organizaron actividades en función de las aspiraciones de los diversos animadores del CKI. Esa tentativa se desplegó en cuatro frentes. El 
primero fue la tallerización. Pablo M. ${ }^{15}$ indica que, "hubo una explosión de gente que decía "yo quiero dar un taller de" y se sumaron un montón de espacios”. Su formato era semanal y no precisaba una cuota monetaria fija, siendo gratuita o a la gorra. Según Omar S. ${ }^{16}$, quien dictó un taller de teatro, algunas propuestas duraban "unos pocos meses y [reunían] grupos reducidos”. Con la misma suerte corrieron las artes visuales enseñadas por $\mathrm{Faca}^{17}$, cuyo "taller de plástica urbana no prosperó”. Por el contrario, las artes circenses -provenientes de la Fiesta del Fuego de 1996- fueron exitosas entre un creciente público interesado por los malabares y las acrobacias. Junto a los alumnos externos, los colaboradores del Galpón Okupa hicieron uso de las instancias tallerizadas. Ivana R. enuncia que "llegamos a ser 15 artesanos en el taller comunitario de artesanías”. En esa línea, Amalia D. expresa que "tuvimos la suerte de tomar un taller de artesanías" con el que "viajamos por Latinoamérica”. Los espacios de formación incluyeron ajedrez, dibujo (fig. 3), guitarra, trompeta, lectura y tango.

Figura 3. Talleres de ajedrez y dibujo

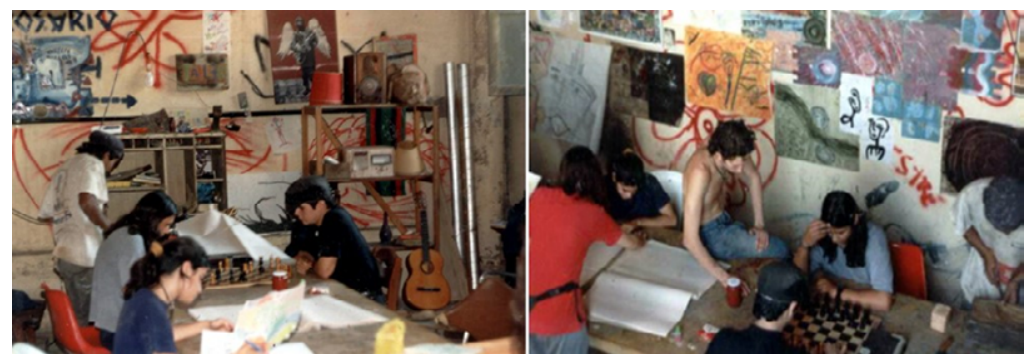

Fuente: fotografía de Inés Martino.

El segundo frente consistió en la celebración de veladas. Los ciclos de cine fueron relativamente convocantes debido, en gran parte, a su gratuidad. Txatxi comenta: "activamos un ciclo de cine porque conseguimos una pantalla grande”. También las

15 Artesano y fotógrafo, participante del Galpón Okupa. Entrevista personal, 04/06/2015.

16 Actor y dramaturgo, participante del Galpón Okupa. Entrevista personal, 12/08/2019.

17 Artista visual y diseñador, participante del Galpón Okupa. Entrevista personal, 10/12/2017. 
obras de teatro ganaron popularidad. Omar S. versionó "Los días felices” de Samuel Beckett y "La voz humana” de Jean Cocteau, "muy bien recibidas, con mucho público en las gradas que armamos". Asimismo, se presentaron instalaciones y performances de circo y de danza. El tercer frente fue la organización de reuniones. Distintas agrupaciones y movimientos sociales, como Hijos e Hijas por la Identidad y la Justicia contra el Olvido y el Silencio (HIJOS) y la Asamblea Permanente por los Derechos Humanos (APDH) realizaron algunos encuentros allí. Por su parte, la Red de Solidaridad con Chiapas intentó apuntalar la práctica asamblearia en el Galpón Okupa. Amalia D. rescata "la imagen del galpón lleno, lleno de gente [...] en un encuentro de organizaciones referenciadas con el zapatismo, en el que se llegó a cocinar para más de 200 personas”. El cuarto y más popular frente concernió a la música en vivo. En una búsqueda de escenarios que se remontaba al retorno democrático de 1983, decenas de conjuntos musicales pusieron sus expectativas en el espacio. El inmueble de altos techos y gruesos muros ofrecía una acústica conveniente. El gran salón central devino sala de conciertos con capacidad para 300 espectadores. Txatxi rescata "la intención de hacer recitales" y entiende que "el lugar era una referencia: la gente ya sabía que ahí se hacían movidas todos los fines de semana”. Para diciembre de 1997, el escenario fue ampliado y remodelado, espejando el patrón habitacional elevado del CKI. Eduardo V. ${ }^{18}$, uno de sus constructores, lo concibe como "un entrepiso hecho escenario, una estructura de tres pisos, con un andamio alto y dos laterales". Se estima que se sucedieron unos 70 recitales en el CKI.

\section{Conflictos}

Durante su primer año de existencia, con una población semi-estable y una fuerte circulación de colaboradores, el Galpón Okupa acrecentó su grilla de actividades. Sin embargo, el espacio nunca estuvo exento de amenazas. En principio, el funcionariado municipal intentó persuadir a los participantes del CKI para que abandonen el inmueble. Pablo M. repone un confuso intercambio:

18 Músico, participante del Galpón Okupa. Entrevista personal, 05/01/2019. 
Hubo una mediación con Control Urbano cuando recién se empezaba a gestar el Galpón. Todavía no había habido ningún recital ni ningún malabarista haciendo nada. Cayeron con una trabajadora social y tres funcionarios municipales, a negociar como lo harían con una familia de la villa. Nos ofrecieron veinte chapas, doscientos bloques y colchones a cambio de que nos vayamos. Y encuentran a un montón de personajes bastante formados, que se plantan y les tiran argumentos. Los tipos quedan descolocados, totalmente en offside y Modarelli ${ }^{19}$ se enoja y se va a las puteadas sin terminar de definir la mediación. [...] Desde entonces la Municipalidad deja de tener intentos de negociación.

La expedición negociadora fue a la zaga de lo que entendía como la rudimentaria población de una carcasa ferroviaria. En cambio, se careó con los litigantes animadores de un centro cultural. La visión de la ocupación como el desesperado paliativo a un problema habitacional puede ser cotejada. Zeta alude a "gente de la calle", pero Mauro F. relativiza: "había chicos bien, que se armaban un bolsito y cruzaban desde los edificios caretas de enfrente". Txatxi complejiza el cuadro: "cayó el Comando de la 3ra y dejó a un tipo en silla de ruedas [...] un croto, pero esto no era un crotario". Amalia D. corrobora la semblanza del "croto que trajeron de la Comisaría 3ra”. El contrapunto incorpora a una Seccional de Policía que interpretaba al Galpón Okupa como plaza de guarecimiento humano. El mosaico social que combinaba a los organizadores culturales con personas sin hogar que pasaban algunas noches en el sitio, dificultaba la legibilidad gubernamental (Scott, 1998) de la experiencia okupa.

De todas formas, las visitas de los auxiliares de la ley no descuidaron el recurso a la violencia. Disuelto el estupor de la malograda mediación inicial, advinieron la intimidación y la coacción. El CKI llegó a cargar con seis intentos de desalojo sobre sus espaldas. Uno de los últimos episodios involucró a "diecisiete policías en seis móviles [en] un inusitado operativo para la detención de cuatro jóvenes que

19 Ubaldo Modarelli, Director de Control Urbano durante la intendencia de Hermes Binner (1995-2003). 
viven en un galpón de la zona”. ${ }^{20}$ Las tácticas defensivas de los participantes del Galpón Okupa fueron de dos tipos. En primer lugar, podían bloquear puertas y ventanas, hasta reunir la masa crítica suficiente para aguantar el embate. En segundo lugar, "imputaron acciones policiales intimidatorias que nunca fueron reconocidas por la fuerza pública, pero que motivaron la intervención de [...] APDH". ${ }^{21}$

Mientras intentaba mantenerse a flote, el CKI se sumió en un larvado conflicto de intereses. En diciembre de 1997, fuera del radar de sus organizadores culturales, el destino del inmueble se decidió entre la Municipalidad de Rosario y la Academia del Tango de esa ciudad. Las repercusiones del acuerdo celebrado a puertas cerradas rozaron unas pocas columnas editoriales..$^{22}$ A comienzos de 1998, el gobierno blanqueó sus intenciones, desestimando el proyecto del Galpón Okupa y dándole

...el ultimátum a un grupo de jóvenes, identificados como los Okupa para que desalojen un galpón [...] en el que viven y desarrollan distintas actividades artísticas desde hace dos años. [...] la Secretaría de Cultura tiene proyectado realizar ahí la Casa del Tango, un centro del dos por cuatro para todos los rosarinos. [El Secretario de Gobierno] no consideró que la propuesta cultural de los ocupantes sea un factor «a considerar». ${ }^{23}$

A pesar de la rúbrica, el proyecto se encontraba trabado debido a la condición fragmentaria del régimen de propiedad del espacio en conflicto. Un año después de su liquidación en 1995 y un año antes de la ocupación de 1997, los activos del ferrocarril pasaron a manos del Ente Nacional de Administración de Bienes Ferroviarios (ENABIEF) por el Decreto 1383/96. El organismo autárquico asumió la salvaguarda de las extensiones del ferrocarril en todo el país. Por ende, el inmueble caía la jurisdicción del Estado nacional, sustrayéndose de la potestad del Ejecutivo municipal.

20 La Capital, 17/02/1998, "Insólito operativo policial por un caño".

21 Ibíd.

22 Rosario/12, 24/02/1998, "Kultura es una 'X', un espacio vivo en construcción permanente” y 26/02/1998, “Galpón Okupa (réplica)".

23 La Capital, 24/03/1998, "Una ocupación ilegal frena la futura Casa del Tango”. 
La firma en favor de la Casa del Tango obedeció a una optimista especulación. Se esperaba un pronto traspaso de las propiedades del ENABIEF al municipio. Entretanto, la ocupación de la edificación complicó la perspectiva ambicionada por las autoridades. Es verosímil que el carácter extralegal del accionar de los efectivos de seguridad tuviera que ver con el intrincado limbo institucional. Por un lado, explicaría la modalidad solapada de los operativos, que incluían a personal de civil y solían ampararse en la nocturnidad. Por otro, le daría peso a la paradójicamente baja densidad de tentativas de desahucio. Son elocuentes los exiguos 400 metros que separaban a la Comisaría 3ra del CKI y los largos 18 meses que distribuyeron las incursiones.

Pasados los infructuosos asedios, intervino el fuero con jurisdicción sobre los activos ferroviarios. El 7 de julio de 1998, el Juzgado Federal No 2 de Buenos Aires instruyó el vaciamiento del Galpón Okupa. El diario La Capital24 recabó las impresiones y las respuestas de los afectados. Los okupas solicitaron más tiempo para negociar argumentando que, hasta entonces, desconocían los pormenores de la situación. Querían "demostrarles a la gente y a la Municipalidad [un] proyecto cultural distinto y alternativo”. La letrada que tomó el patrocinio del CKI, declaró que "hasta [entonces] no había llegado un pedido especial" del ENABIEF. Los voceros de la APDH denunciaron la maniobra como "una estrategia de la Municipalidad para no quedar ellos como los responsables del desalojo”.

\section{Visibilización}

Por sí misma, la campaña de demostración del proyecto cultural del Galpón Okupa no habría trascendido la escala rosarina. No obstante, recibió el auxilio mediático derivado de una tragedia. María Soledad Rosas, una joven porteña de 24 años, había viajado a Europa en 1997. Terminó habitando en El Asilo, un squat turinés. El 10 de julio de 1998, tras ser encarcelada bajo una falsa acusación, se quitó la vida. Las condiciones de su deceso y su nacionalidad le valieron la atención de los medios nacionales. Los formadores de opinión volvieron

24 La Capital, 15/07/1998, “Todavía no hay definición en la situación de los Okupa”. 
las miradas sobre el propio terruño, buscando a "los primos argentinos" de María Soledad. ${ }^{25}$ En esa pesquisa, hallaron al Galpón Okupa. ${ }^{26}$ Llamativamente, la exposición mediática hizo hincapié en dos factores que parecían singularizar la experiencia rosarina. El primero: en ese momento, posiblemente el CKI constituía el único centro cultural okupa del país con características análogas a El Asilo italiano, consistentes en la tallerización de práctica artística y la realización de recitales. ${ }^{27} \mathrm{El}$ segundo: aparentemente, esa similitud no se debía a una suerte de “imitación trasnacional” (Martínez, 2012; Iñigo, 2019). La revista Rolling Stone explicaba que "[l]a noticia no llegó a los okupas de Rosario. Simplemente, porque no compran diarios, no escuchan radio ni ven televisión”. ${ }^{28}$ Los interiores del espacio y sus actividades fueron retratados en esa nota (fig. 4).

\section{Figura 4. Malabares en el Galpón Okupa}

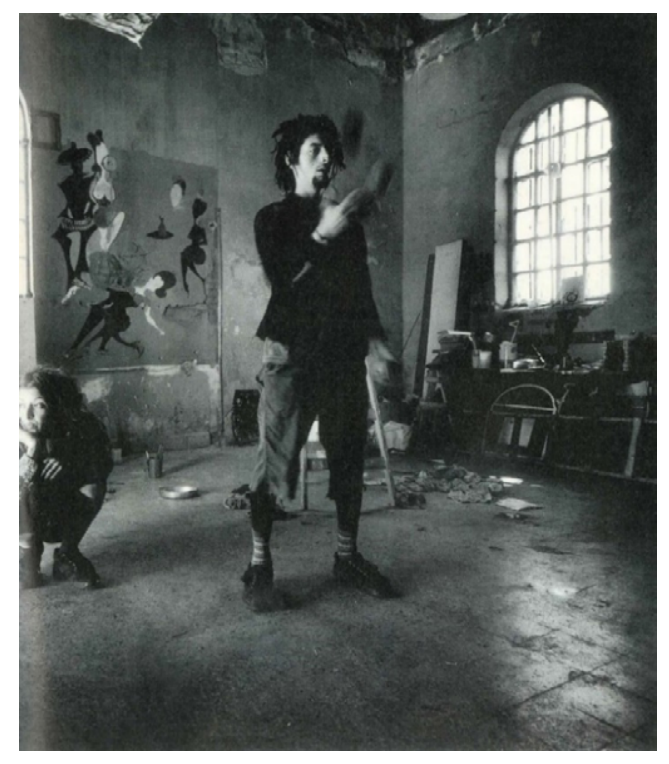

Fuente: Rolling Stone (Argentina), 08/1998.

25 Clarín, 30/08/1998, "La Sole y sus primos argentinos".

26 Por ejemplo, Clarin, 15/07/1998, "Squatters locales” y Página/12, 16/07/1998, "Los squatters rosarinos en batalla por un galpón”.

27 Incluso puede rastrearse la influencia del CKI en centros culturales okupas posteriores. En el caso de Rosario, La Panadería, Rosario Norte y La Peluka del Pelukero. En el caso de Buenos Aires, Trivenchi (Godoy, 2021b).

28 Rolling Stone (Argentina), agosto de 1998, “Okupas en Rosario”. 
Por su parte, el programa televisivo "Memoria” realizó una cobertura a dos puntas. Mandó un móvil a Rosario e invitó a exponentes de los okupas a los estudios de Buenos Aires. En el piso del canal, Ferky declaraba que "nosotros ocupamos un lugar, no para que sea nuestro, sino para que sea de todos”. En la locación rosarina, Txatxi posicionaba a la ocupación como "una forma de abrir un espacio cerrado a la comunidad". Un zócalo del show rezaba "Okupas, ¡una nueva forma de guerrilla!” (fig. 5). ${ }^{29}$ Gracias al caso de María Soledad Rosas y la exposición mediática resultante, el CKI articuló tácticamente su visibilidad amplificada para dar a conocer su proyecto cultural.

\section{Figura 5. okupas rosarinos en el programa "Memoria”}

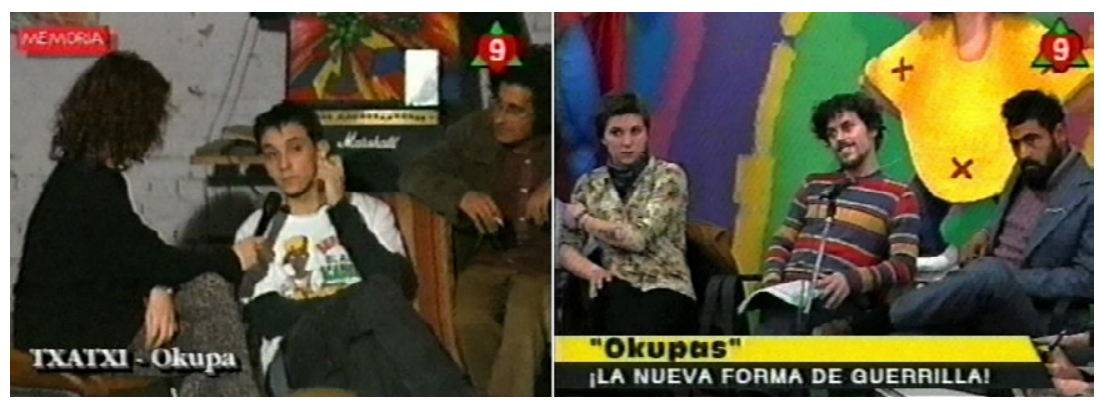

Fuente: archivo personal de Txatxi.

\section{Desalojo}

Entre la tragedia italiana y el desalojo del Galpón Okupa, mediaron 33 días. En cierto modo, la muerte de la muchacha le insufló vida al centro cultural, mientras la feria judicial postergaba el desenlace final. Unos pocos residentes se atrincheraron pacíficamente a la espera del arribo federal. ${ }^{30} \mathrm{La}$ abogada acompañó a sus representados, aclarándoles que toda resistencia excedía el marco judicial del pleito. En el ojo de la tormenta, los okupas destilaban su indignación contra la Municipalidad, que se había "lavado las manos":

29 Grabación del programa "Memoria”, archivo personal de Txatxi.

30 La Capital, 12/08/1998, “Los Okupas sólo esperan”. 
Durante un año y pico estuvimos negociando de buena fe con funcionarios de segunda línea, creyendo que el dueño de los galpones era el municipio. No sabíamos nada de esto hasta que un día cayó una delegación del juzgado federal. ${ }^{31}$

El 12 de agosto de 1998, a las 7:30 de la mañana, el Galpón Okupa fue desalojado. "En tan solo 40 minutos", ${ }^{32}$ el interior de la edificación fue vaciado. El "impresionante operativo" fue encabezado por "un grupo de elite de la Policía Federal y unos treinta gendarmes". ${ }^{33}$ En la retaguardia, la comitiva se completó con media docena de camiones y patrulleros, más dos ambulancias del Sistema Integrado de Emergencias Sanitarias de la ciudad (SIES). Del otro lado del conflicto, Txatxi aclara:

Estábamos esperándolos. El día del desalojo, estaba la cámara [que teníamos] y se filmó todo. ${ }^{34}$ Fue un desalojo por parte de la justicia federal, con policías federales que dejó un grupo de gendarmes cuidando. Tipos encapuchados, armados. Nosotros habíamos resistido simbólicamente, porque mantuvimos todo cerrado, pero no violentamente.

La grabación muestra, frente al CKI, a 4 funcionarios de traje y un semicírculo de gendarmes y policías pertrechados con equipamiento táctico. Uno de los hombres trajeados se dirige a los ocupantes: "les vamos a dar tres minutos para que ustedes abran la puerta y desalojen [...] caso contrario, vamos a tener que hacer uso de la fuerza pública”. En respuesta, desde adentro de la edificación empiezan a sonar -in crescendo- instrumentos de viento. Con una tenaza, los uniformados fuerzan su camino hacia el interior. La cámara los persigue. La lente no logra enfocar la situación debido a los movimientos de las corridas. Se escuchan gritos, hasta que una voz exclama "ya está, ganaron, ganaron, ganaron”. Acto seguido, desde el portón principal egresa una docena de jóvenes, llevando objetos a cuestas. Uno de ellos toca una trompeta en la cara de los uniformados y los funcionarios.

31 Página/12, 12/08/1998, "Los Okupa van a resistir en forma pacífica el inminente desalojo”.

32 Página/12, 13/08/1998, "Rosario ya no tiene Okupas".

33 La Capital, 13/08/1998, "Los Okupa fueron desalojados en un impresionante operativo policial”.

34 Parte de esa cinta fue incorporada al documental Resis-T. 
Los actores involucrados vivieron el acontecimiento desde varios lugares. Mauro F. menciona el cerramiento: "tapiamos todas las puertas, pero ya mucho no se podía hacer”. Pablo T. resalta la desmesura del desahucio, que requirió el cercamiento del "centro en un radio de diez cuadras a la redonda [...] por siete y ocho pibes”. Amalia D. recalca: "en ese momento, solamente había dos o tres de los chicos iniciales". Eduardo V. califica al episodio de "violento, porque nos rompieron todo". En consonancia, Omar S. recuerda que "a algunos de los chicos los sacaron de los pelos". No conforme con su declaración previa, que quitaba de toda consideración al desenvolvimiento cultural del CKI, el Secretario de Gobierno volvió a embestir: "nunca tuvimos propuestas para ellos". ${ }^{35} \mathrm{Al}$ parecer, "la primera noche [de los ex okupas] fuera del viejo edificio ferroviario transcurrió con absoluta normalidad y sin que se produjeran incidentes”. ${ }^{36}$ Los jóvenes acamparon una semana frente al inmueble vacío (fig. 6), para luego dispersarse.

\section{Figura 6. Gendarmes y acampe frente al ex Galpón Okupa}

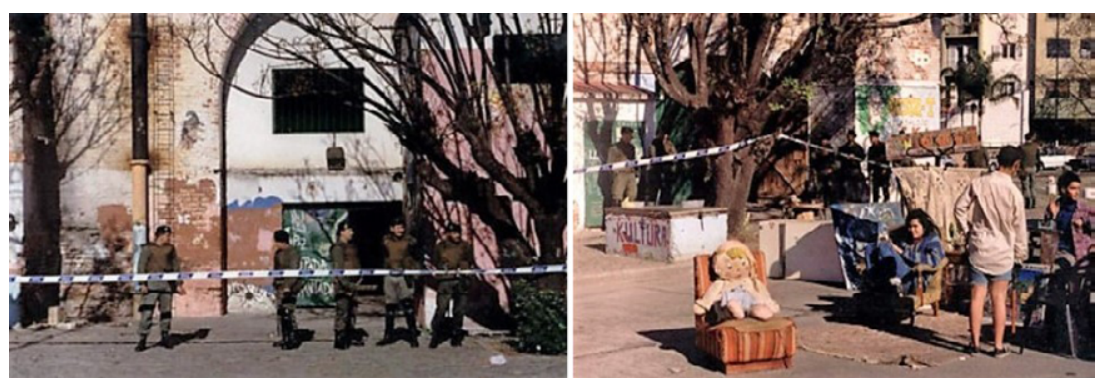

Fuente: fotografías de Inés Martino.

35 La Capital, 13/08/1998, "Los Okupa fueron desalojados en un impresionante operativo policial".

36 La Capital, 14/08/1998, "Los Okupa, al aire libre”. 


\section{Frente costero: clausura y absorción}

Luego del desalojo, al municipio le restaba esperar noticias positivas provenientes del ENABIEF. De todas maneras, se anunció que los nuevos adjudicatarios tomarían posesión del galpón en lo inmediato. Si bien "el acuerdo no implica que la Municipalidad regale el inmueble” había que "relevar el edificio para elaborar un proyecto definitivo y conseguir los sponsors". ${ }^{37}$ A fines de octubre se realizó un festejo por la entrega de la propiedad, que incluyó un acto y el baile de parejas de tango en vivo. "El público, en su mayoría de edad avanzada, respondió con aplausos”. ${ }^{38}$ La franja etaria de los asistentes al evento contrastaba notablemente con los convocados por los talleres y recitales que, hasta un mes atrás, poblaban el edificio. El presidente de la Academia del Tango, explicitó los pasos a seguir:

Involucrar al tango en una red cultural [ya que] la popularidad de este género en el exterior es increíble. [...] Desconozco la filosofía de los okupa [...] pero si es gente joven que busca crear libremente, entonces compartimos una misma idea y se tiene la mejor buena voluntad para incorporarlos en las actividades [...] hace mucho tiempo que se tenía esta idea y nunca hubo intención de interferir en los proyectos de otras personas. ${ }^{39}$

De manera predecible, ninguno de los animadores del ex CKI se apersonó ante su reemplazo. La Casa del Tango convocaría a artistas pertenecientes al género y las distintas ramas del folklore. Sin embargo, pasaron meses sin señales de un pronto estreno del centro cultural. En relación a la entrega simbólica de llaves, los desalojados y sus patrocinadores denunciaban el proyecto oficial. La APDH culpaba al gobierno "de avanzar sobre este espacio que no le pertenece para instalar la Casa del Tango". ${ }^{40}$ Moroco protestaba

37 El Ciudadano, 09/10/1998, "La Academia del Tango tomará posesión la semana próxima del galpón de Wheelwright y España. Los okupas sacaron ayer sus pertenencias del lugar.

38 El Ciudadano, 27/10/1998, "La Intendencia entregó ayer los galpones de España y Wheelwright a la Academia del Tango".

39 Ibíd.

40 Página/12, 12/08/1998, "Los Okupa van a resistir en forma pacífica el inminente desalojo”. 
ante las cámaras: "supuestamente nos desalojaron porque se iban a empezar a hacer las obras ya [,] después de diez meses del desalojo, todavía el galpón está vacío". ${ }^{41}$

El traspaso de los terrenos del ENABIEF a la Municipalidad de Rosario se concretó el 22 de septiembre de 1999. El Ente firmó "la transferencia onerosa de terrenos ubicados en la costa central, sobre Wheelwright desde Entre Ríos hasta Oroño". ${ }^{42}$ El convenio de pago superaba los 11 millones de pesos y se diseminó en 19 cuotas anuales. Por su parte, el problema financiero de la Academia del Tango estribaba en la dificultad para "conseguir sponsors" en un contexto de recesión. Con una parcial estabilización del ciclo económico, los tempranos 2000 pusieron en marcha la reconversión edilicia. En octubre de 2004, el Concejo Deliberante declaró al tango patrimonio cultural y artístico de Rosario (Ordenanza 7737). Dos meses después, el centro cultural se presentó en sociedad (fig. 7).

Después de siete años [...] se puso en marcha ayer el postergado proyecto de la Casa del Tango, en España y Wheelwright. Luego de un proceso de restauración, las viejas instalaciones ferroviarias de la antigua estación de trenes Rosario Central fueron recicladas y pensadas como un lugar para los amantes del dos por cuatro. La idea [...] es ofrecer un sitio para la preservación de la tradición tanguera. ${ }^{43}$

Dispuesto para el disfrute recreativo y la atracción turística, el dispositivo cultural fue posicionado en naciente waterfront. Según el sitio oficial de la Municipalidad de Rosario $^{44}$, la Casa del Tango reconoce un único pasado como "un galpón destinado a cargar de agua a las máquinas de los trenes”. Su nueva función sería la promoción de "la cultura del tango en todas sus manifestaciones”.

41 Testimonio extraído del documental Resis-T.

42 La Capital, 23/09/1999, "El Enabief oficializó el traspaso de tierras ribereñas al municipio".

43 La Capital, 12/12/2004, "Se inauguró la Casa del Tango".

44 Rosario.gob.ar: bit.ly/CasaTango 
Figura 7. Casa del Tango

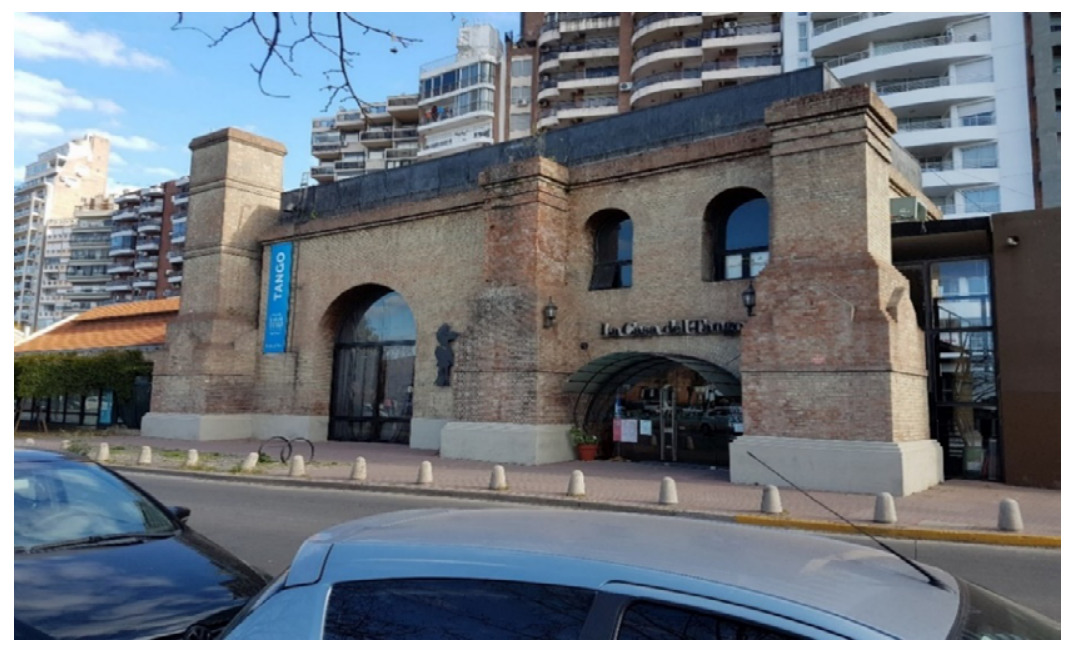

Fuente: fotografía propia.

A pesar de su desalojo del inmueble ferroviario, la experiencia del CKI con las artes performáticas fue parcialmente absorbida por el gobierno. En 2001, el marco de un subsidio del Banco Interamericano de Desarrollo (BID), un nuevo espacio artístico se radicó en un galpón portuario, a unos dos kilómetros al sur del ex Galpón Okupa. Según su director, Marcelo P. ${ }^{45}$, el proyecto consistía en "Artes Urbanas, entendidas como un espacio donde los artistas pueden apropiarse de cualquier espacio público y pueden hacer una función”. Con la Municipalidad de Rosario como garante del financiamiento del BID, ese proceso terminó con la formación de la Escuela Municipal de Artes Urbanas (EMAU), oficializada en 2006 (Godoy, 2020). Algunos ex participantes del CKI fueron convocados para enseñar en la nueva Escuela. Pablo T., quien pasó a formar parte de la planta municipal a través de la EMAU, comenta que "éramos varios [del Galpón Okupa] los que estábamos ahí [...] era algo que habíamos intentado hacer motu proprio y no logramos avanzar [...] ahora lo puedo decir, en ese momento lo criticaba”. Uno de sus

45 Actor callejero y artista circense, director de la Escuela de Artes Urbanas. Entrevista personal, 18/09/2014. 
compañeros de experiencias, Tati ${ }^{46}$, arriesga una genealogía posible: "la Fiesta del Fuego, el Galpón, [...] nos llevaron a las Artes Urbanas”.

En cierto sentido, la apreciación del Secretario de Gobierno en 1998 es contrastable con el desenlace de 2006. La sentencia que desestimaba "la propuesta cultural de los ocupantes [como] un factor a considerar”, resultó paradójica. Las Artes Urbanas, predominantemente circenses y de notable proximidad genealógica con el CKI, se transformaron en una insignia de las políticas culturales del municipio. Al parecer, la "propuesta" fue "considerada" en detrimento de sus condiciones socioculturales de posibilidad: una okupación urbana. Junto a la Casa del Tango, la EMAU fue uno de los dispositivos culturales del frente costero de Rosario (fig. 8). Ambas estructuras, una ferroviaria y otra portuaria, fueron rehabilitadas con nuevas funciones que, por clausura o absorción, se relacionan con la historia del Galpón Okupa.

\section{Figura 8. Galpón portuario donde se encuentra la EMAU}

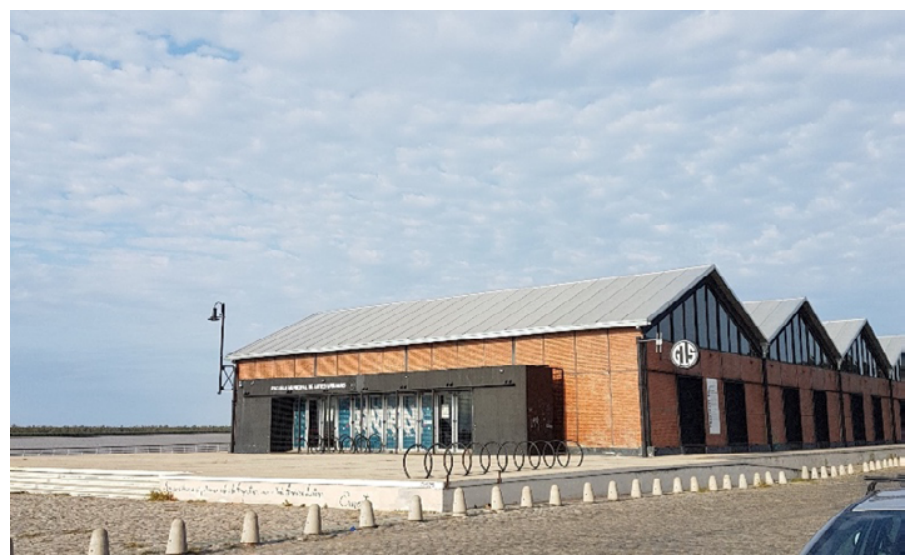

Fuente: fotografía propia.

46 Artista circense, participante de la Fiesta del Fuego y del Galpón Okupa. Entrevista personal, 18/12/2014. 


\section{Reflexiones finales}

Este trabajo intentó aproximarse a las implicancias del Galpón Okupa o Centro Kultural Independiente para la Rosario post-industrial, a través de distintos episodios de su corta historia. Su ocupación fue posibilitada por la desafectación y el abandono de la interfaz ferroportuaria de la ribera rosarina. La caducidad del perfil logístico agroexportador de la ciudad-puerto, colocó a diversas estructuras y terrenos en una disponibilidad tácita. Las prácticas artísticas de los primeros animadores del Galpón Okupa moldearon su perfil de centro cultural. Sus propuestas se inclinaron fuertemente a la tallerización artística, la celebración de veladas, el sostenimiento de asambleas y la realización de recitales.

Si bien se encontró amenazado desde sus inicios por las fuerzas policiales, a comienzos de 1998 el CKI entró en conflicto con un proyecto cultural oficial: la Casa del Tango. A mediados de ese año, el Galpón Okupa intentó articular tácticamente condiciones que le eran impuestas (De Certeau, 2000). Por un lado, las variaciones en las condiciones del pleito (de la mediación municipal y los allanamientos policiales al ingreso del fuero federal) dilataron su resolución hasta después de la feria judicial. Por otro, la visibilidad otorgada por la explotación mediática de la muerte de Rosas, que construyó la imagen de un Galpón Okupa entre tendencias globalizantes (similitud con un squat turinés) y situadas (singularidad en el contexto argentino).

El desenlace de la disputa se inserta en las transformaciones de la Rosario del último tránsito de siglo. El antiguo galpón ferroviario, sede del CKI entre 1997 y 1998, fue desalojado en favor de un centro cultural oficial. Asimismo, parte de las actividades culturales gestadas en el Galpón Okupa fueron integradas a otro de los dispositivos culturales del waterfront. Ambos episodios remiten a desarrollos urbanos post-industriales y, en este caso, post-ferroportuarios. Por un lado, la creación de la Casa del Tango responde a un modelo de gobernanza público-privada (Stoker, 2004) y a la rehabilitación urbana a partir del impacto global del tango (Carman, 2006). Por otro, la fundación de la EMAU 
coloca a las artes performáticas circenses -practicadas y perfeccionadas en el CKI- como parte de la oferta cultural de una ciudad creativa (Florida, 2005).

En suma, la historia del Galpón Okupa representa una experiencia de apropiación y transformación autogestiva de un espacio urbano en decadencia. Juega un papel complejo en la formación de las artes performáticas contemporáneas en su ciudad, oficializadas posteriormente con el nombre de Artes Urbanas. Conforma un episodio inserto en el clivaje entre la caducidad de la urbe industrial y el advenimiento de la ciudad de servicios. Habita intersticialmente en la centralidad costera, waterfront y vidriera promocional de la Rosario post-industrial.

\section{Referencias bibliográficas}

Aboal, D., Crespi, G., y Rubalcaba, L. (Eds.) (2015). La innovación y la nueva economía de servicios en América Latina y el Caribe: Retos e implicaciones de política. Montevideo: Banco Interamericano de Desarrollo.

Bruttomesso, R. (1993). Waterfronts. A new frontier for cities on water. Venecia: Citta D’Acqua.

Bossio, V. (2019). “iMe caso y me voy!”: migraciones transnacionales femeninas desde el Caribe hispánico hacia Italia. Collectivus, Revista de Ciencias Sociales, 6(1), 135-154. https://doi.org/10.15648/Coll.1.2019.8

Carman, M. (2006). Las trampas de la cultura. Los intrusos y los nuevos usos del barrio de Gardel. Buenos Aires: Paidós.

Cattaneo, C., y Martínez, M. (2014). The Squatters' Movement in Europe. Commons and Autonomy as Alternatives to Capitalism. Londres: Pluto Press.

Craig-Smith, S., y Fagence, M. (Eds.) (1995). Recreation and tourism as a catalyst for urban waterfront redevelopment. Londres: Praeger.

De Certeau, M. (2000). La invención de lo cotidiano. 1 Artes de hacer. México: Universidad Iberoamericana.

Fedele, J., y Roca, L. (2012). Proyecto urbano y fragmentación de la ciudad: el caso de los terrenos ferro-portuarios en Santa Fe. Cuaderno Urbano, 12(12), 43-69. 
Fontalvo, R., y Díez, A. (2021). Cartografías de la migración de retorno en Colombia. Evolución y patrones territoriales en el departamento del Atlántico. Collectivus, Revista de Ciencias Sociales, 8(1), 137-154. https://doi.org/10.15648/ Collectivus.vol8num1.2021.2959

Florida, R. (2005). Las ciudades creativas. Por qué donde vives puede ser la decisión más importante de tu vida. Barcelona: Paidós.

Iñigo, L. (2019). Educación para la preservación del medio ambiente. Collectivus, Revista de Ciencias Sociales, 6(1), 215234. https://doi.org/10.15648/Coll.1.2019.12

Galimberti, C. (2015). La reinvención del río. Procesos de transformación en la ribera de la Región Metropolitana de Rosario, Argentina. Rosario: UNR Editora.

Giglia, A. (2012). El habitar y la cultura. Perspectivas teóricas y de investigación. Barcelona: Anthropos.

Godoy, S. (2019). La(s) cultura(s) sobre el río. Gubernamentalidad, prácticas artísticas y habitares. Tesis de Doctorado. Facultad de Humanidades y Artes, Universidad Nacional de Rosario.

Godoy, S. (2020). A ambas orillas de las artes performáticas: dos casos de territorialización cultural del paisaje ribereño en Rosario. A\&P Continuidad, 7(12), 76-87.

Godoy, S. (2021a). Artes de Habitar. Intersticios culturales en la renovación costera de Rosario. Buenos Aires: TeseoPress. Disponible en: teseopress.com/artesdehabitar

Godoy, S. (2021b). Habitar con el circo. Prácticas espaciales y resonancias artísticas a partir de Rosario (Argentina). Artilugio, (7), 30-46.

Guber, R. (2011). La etnografía: Método, campo y reflexividad. Buenos Aires: Siglo XXI.

Harvey, D. (1998). La condición de la posmodernidad. Investigación sobre los orígenes del cambio cultural. Buenos Aires: Amorrortu.

Harvey, D. (2009). El derecho a la ciudad. New Left Review, (53), 23-39.

Janoschka, M. (2016). Gentrificación, desplazamiento, desposesión: procesos urbanos claves en América Latina. Revista INVI, 31(88), 27-71. 
Lefebvre, H. (2013). La producción del espacio. Madrid: Capitán Swing. MacCannell, D. (2007). "Staged Authenticity”. American Journal of Sociology, 79(3), 589-603.

Marshall, R. (Ed.) (2001). Waterfronts in Post-Industrial Cities. Nueva York: Spon Press.

Martínez, M. (2012). The Squatters' Movement in Europe: A durable struggle for social autonomy in urban politics. Antipode, 45(4), 866-887.

Martínez, M. (2020). Squatters in the Capitalist City: Housing, Justice, and Urban Politics. Nueva York: Routledge.

Masagualli, N., y Bolaño, O. (2017). Alternativas de poder político en los movimientos sociales-rurales de Colombia: caso organización indígena del norte del Cauca. Collectivus, Revista de Ciencias Sociales, 4(2), 36-54. https://doi. org/10.15648/Coll.2.2017.3

Meyer, H. (1999). City and Port: Transformation of Port Cities: London, Barcelona, New York and Rotterdam. Rotterdam: International Book.

Portelli, A. (1991). "Lo que hace diferente a la historia oral", en D. Schwartzstein (Comp.), La historia oral. Buenos Aires: Centro Editor de América Latina.

Rabotnikof, N. (1997). El espacio público y la democracia moderna. México: IFE.

Roldán D., y Castillo, T. (2020). Derecho a la ciudad, acumulación y desterritorialización. Espacio público y pescadores en Rosario. Bitácora Urbano Territorial, 30(3), 149-161.

Roldán, D., y Godoy, S. (2017). Antes del espacio público: una historia de los espacios verdes y libres de la ciudad de Rosario (1900-1940). Cadernos de História, 18(28), 150-177.

Roldán, D., y Godoy, S. (2020). Conflictos territoriales y culturales en la renovación del frente costero, Rosario (Argentina). Eure. Revista Latinoamericana de Estudios Urbano Regionales, 46(138), 95-116.

Sabaté, J. (2010). De la preservación del patrimonio a la ordenación del paisaje: intervenciones en paisajes culturales (Europa-Latinoamérica). Labor e Engenho, 4(1), 10-25. 
Salvatori, S., y Terrón, T. (2019). L’approccio intersezionale e quello transnazioanle nello studio dei flussi migratori: elementi per una proposta analitica. Collectivus, Revista de Ciencias Sociales, 6(1), 35-46. https://doi.org/10.15648/Coll.1.2019.3

Scott, J. (1998). Seeing Like a State. New Haven: Yale University Press.

Smith, N. (2013). La nueva frontera urbana. Ciudad revanchista y gentrificación. Madrid: Traficantes de Sueños.

Stoker, G. (2004). Transforming local governance. Nueva York: Palgrave.

Vera, P. (2015). Estrategias patrimoniales y turísticas: su incidencia en la configuración urbana. El caso de Rosario. Revista Territorios, (33), 83-101.

Ward, S. (1998). Selling Places. The marketing and promotion of towns and cities 1850-2000. Londres: Routledge.

Zukin, S. (2000). The Cultures of Cities. Cambridge, MA: Blackwell. 